\title{
Requalificação Urbana e Novas Centralidades na Cidade de Quelimane, Moçambique
}

\section{Urban Re-qualification and New Centralization in Quelimane, Mozambique}

\author{
Klayde Karmila Gaspar Evaristo \\ Universidade Pedagógica de Quelimane \\ Quelimane, Moçambique \\ João Carlos Mendes Limaii \\ Universidade Pedagógica de Quelimane \\ Quelimane, Moçambique
}

\begin{abstract}
Resumo: Este artigo analisa a reestruturação urbana decorrente das atividades econômicas que vêOm sendo desenvolvidas por os agentes econômicos na cidade de Quelimane. Nele, fundamentam-se a urbanização e a expansão da cidade; a dinâmica econômica e a produção do espaço urbano, a reestruturação da cidade, a difusão do comércio e dos serviços especializados, bem como as desigualdades e precariedades socioespaciais. O estudo procura demonstrar como são retratadas as questões relacionadas com as atividades econômicas, os agentes e papéis destes intervenientes no processo de reestruturação urbana. Para o efeito, foi usada a pesquisa exploratória com abordagem qualitativa, tendo sido aplicadas entrevistas a respondentes-chaves para obter informação necessárias para a condução da pesquisa. Os resultados da pesquisa revelaram que a reestruturação urbana na cidade de Quelimane no passado recente decorreu de forma informal e espontânea e, ainda hoje, a produção do espaço urbano e as formas de sua expansão, é reflexo da conjuntura dos modelos de ocupação do mesmo; que as atividades econômicas de maior expressão nesse processo são as pequenas e médias empresas do ramo hoteleiro, de fornecimento de bens e serviços especializados, de comércio, de construção civil, de entretenimento e de transportes de passageiros, incluindo os táxis de bicicleta. O estudo sugere que, no processo de reestruturação urbana, o planificador físico seja mais cauteloso, rigoroso e minucioso para acomodar os interesses dos excluídos, bem como que o processo de reestruturação urbana e da expansão da cidade siga os modelos de requalificação urbana definidos não apenas nas normas instituídas no país, mas também os saberes locais, nesta era da globalização para acomodar os sistemas funcionais políticos, culturais e socioeconômicos.
\end{abstract}

\footnotetext{
' Licencianda em Gestão Ambiental e Desenvolvimento Comunitário na UPQ. klaydekarmilageva0@gmail.com

ii Doutor em Geografia. Prof. Auxiliar na UPQ. jocarlima57@gmail.com
} 
Palavras-chave: Quelimane; Reestruturação Urbana; Desconcentração Urbana; Meio Rural; Meio Urbano; Moçambique.

\begin{abstract}
This essay analyses urban restructuring caused by the introduction of new economic activities undertaken by private sector agents in Quelimane, Mozambique. The research investigated the process of urbanization and expansion of the city, economic dynamics and production of urban space, the growth of commerce and specialized services, social inequality and socio-spatial precariousness. The study seeks to demonstrate how issues related to the economic activities, agents and roles of actors in the process of urban restructuring are portrayed. A qualitative approach was used, involving interviews of key actors. The research revealed that urban restructuring in Quelimane in the recent past occurred informally and spontaneously as it still does today. Urban expansion reflects occupational models, the most expressive being economic activities undertaken by small and medium enterprises involving hotels, the provision of specialized goods and services, commerce, civil construction, entertainment and passenger transport in bicycle taxis. The study suggests that in the process of urban restructuring planners must be more careful to embrace excluded actors. Similarly, the process of urban restructuring and city expansion must follow models of urban re-qualification based not only on official norms but which also take indigenous knowledge into account. This is fundamental in times of globalization in order to accommodate political, cultural and socio-economic functional systems.
\end{abstract}

Keywords: Quelimane City; Urban Restructuring; Urban De-Concentration; Rural Environment,; Urban Environment; Mozambique.

\title{
Introdução
}

A cidade surge a partir da migração de população das áreas rurais para, aos poucos, criarem a urbe, que lenta e gradualmente se estruturam para dar origem à cidade. Por isso a cidade nasce da necessidade de se organizar num dado espaço no sentido de integrá-lo e aumentar a sua independência visando a determinado fim. A partir do momento em que o Homem começou a ter algum domínio tecnológico agrícola, ele deixou de ser nômade, pois o exercício desta atividade impôs algumas divisórias que determinaram, a partir de então, os primeiros aglomerados urbanos (CORRÊA, 2006, p. 34).

O estudo parte de uma análise reflexiva procurando demonstrar como são retratadas as questões relacionadas com as atividades econômicas, os impactos ambientais, os agentes e papéis destes intervenientes no processo de reestruturação urbana, numa altura em que a cidade de Quelimane cresce por extensão, em serviços e economicamente. A partir daí, analisa como se desencadeia a definição e a redefinição dos espaços e suas funções, ao mesmo tempo que se notabilizam problemas de saneamento, bem como as desigualdades de acesso, de oportunidades e de organização espacial dos aspectos sociais e econômicas entre o centro e subúrbio e até mesmo ao nível do mesmo espaço urbano, de acordo com as novas perspectivas da urbanização mundial (SILVA e SPOSITO, 2017). 
Por isso, trata-se de um trabalho que, pela característica da sua temática multifacetada, remete-nos a necessidade de buscar indicadores poliformes para a resposta do problema em questão, e que pela natureza do problema e seus objetivos será analisada numa perspectiva qualitativa assente numa pesquisa exploratória.

O artigo é constituído por três partes, sendo a primeira referente à dinâmica de vida urbana da cidade de Quelimane; a segunda versa sobre o solo urbano como meio de troca e a terceira aborda a questão de restruturação urbana e novas centralidades, como possibilidade.

\section{Dinâmica de Vida Urbana da Cidade de Quelimane}

A cidade de Quelimane localiza-se próximo à costa leste do centro de Moçambique entre os paralelos de $17^{\circ} 52>42^{\prime \prime}$ de latitude $\mathrm{S}$ e $36^{\circ} 53^{\prime} 17^{\prime \prime}$ de longitude $\mathrm{E}$, respectivamente (DINAGECA, 2012). Limita-se a norte com as localidades de Namacata e Maquival pertencentes aos distritos de Nicoadala e Quelimane, respectivamente, a sul pelo Rio Cuacua (Bons Sinais) que o separa do distrito de Inhassunge, a este limita-se com a localidade da Madal e a oeste com a localidade de M'purune, como ilustra a Figura 1.

As cidades moçambicanas no geral confrontam-se com o paradigma de desenvolvimento urbano decorrente da ocupação espontânea e informal das zonas periféricas, as quais avançam mais rapidamente do que o processo instituído de ordenamento territorial dessas urbes. A cidade de Quelimane não constitui exceção. No entanto, estão sendo ensaiadas estratégias para a sua reestruturação e requalificação.

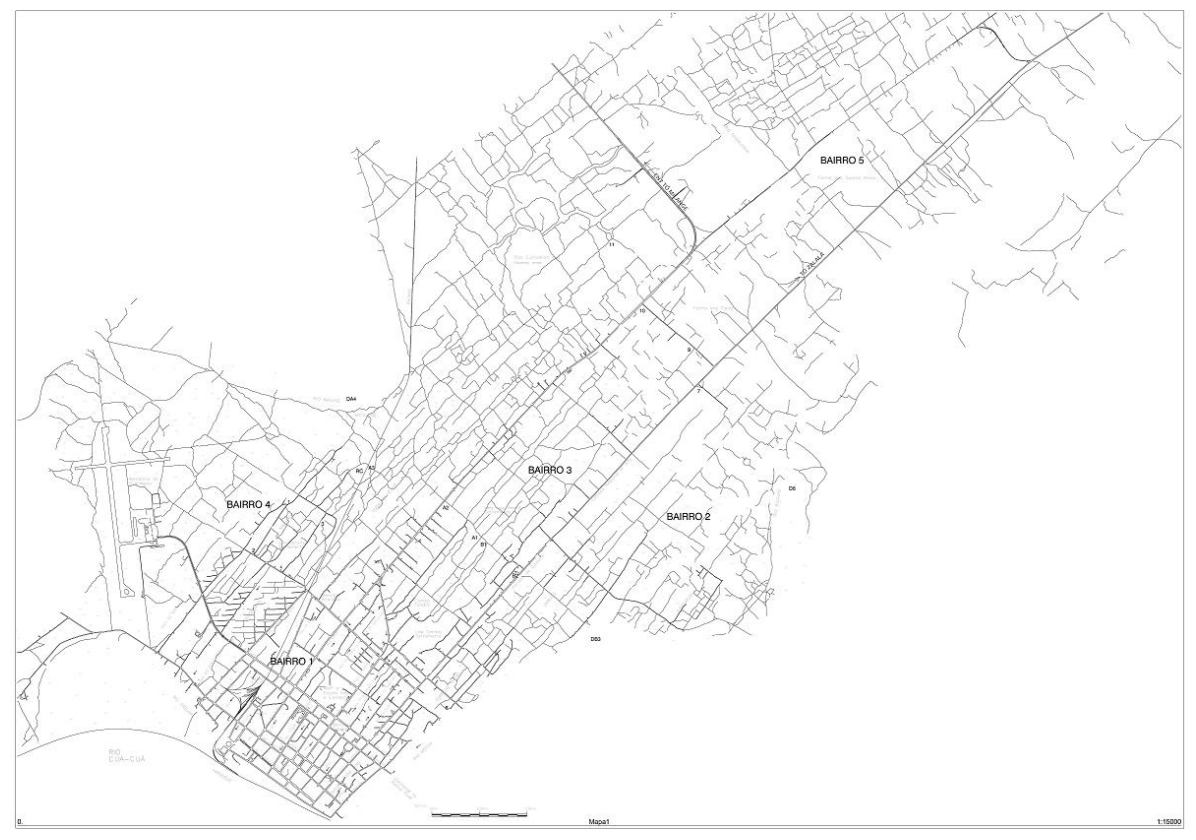

Figura 1 - Mapa de Localização Geográfica da cidade de Quelimane.

Fonte: CMCQ, 2012. 
De acordo com Gottdiener (1993, p.76), "na contemporaneidade da urbanização, verifica-se um amplo processo de reestruturação caracterizado pela 'explosão' das tradicionais formas de concentração urbana e pela emergência de novas formas espaciais e de novas territorialidades dos grupos sociais".

Para o autor, na escala interurbana, o fenômeno da "dispersão urbana" está a "alterar a morfologia urbana tradicional, gerando novas centralidades e novas periferias. $\mathrm{Na}$ escala interurbana e regional, são produzidos novos processos de desconcentração e reiteração espacial da população, das atividades econômicas e da informação sobre o território" (Idem, p. 77).

Neste âmbito, o processo de desconcentração e reafirmação estão a caracterizar as atuais cidades e regiões, sejam elas pequenas ou médias, em que a dispersão urbana se dá através do processo de desconcentração com a abertura de novos espaços para exploração habitacional, ou para bens e serviços especializados e não especializados, devido à ocupação dos espaços e às funções para as quais Ihes são definidas, quer seja formal, seguindo as normas estabelecidas pela postura municipal vigente na urbe, quer seja informal ligado ao saber dos atores e de ocupação espontânea.

De igual modo, verifica-se a situação de reconcentração feita pela ocupação recente dos espaços nos centros urbanos e da reconstrução de algumas infraestruturas para atribuição de novos papéis a tais espaços, já que, durante décadas estas áreas estiveram em situação de subaproveitamento total.

Para o caso da cidade de estudo, este processo deveu-se e deve-se, em parte, a fatores de ordem político-colonial e da guerra dos 16 anos, que confrontou as forças armadas do país com as do movimento de guerrilha da Renamo. De fato, a independência de alguns países, incluindo Moçambique, induziu o abandono dos projetos que os colonos que implementavam nesses países. Com a retirada dos colonos, as cidades ficaram inacabadas e com uma estrutura rural e urbanizada em simultâneo. Portanto, as cidades ficaram com espaços vazios e ainda hoje é possível observar este fenômeno, ao coabitar espaços ocupados com prédios e infraestruturas, de um lado da rua e do outro, casas precárias numa ala completamente degradada, o que Bahia (2004) chamou de uma caraterística híbrida. Mais do que isso, de um lado são visíveis infraestruturas inacabadas onde assentam focos de marginalidade perpetuadas por meninos de rua, mendigos e outros marginais, e do outro lado focos de fecalismo a céu aberto, de prostituição e até de acumulação de lixo que se desenvolvem em terrenos desocupados no centro da cidade, como é o caso da catedral velha, situada na marginal.

Contudo, o município, em parceria com o setor público e privado, tem implementado estratégias para que aos poucos leve ao fechamento desses espaços ausentes existentes na cidade com a construção de hotéis, prédios mistos (serviços e atividade comercial no andar térreo e habitação nos andares acima), residenciais, lojas, supermercados, discotecas, parques infantis, de lazer e de estacionamento de viaturas etc., de modo a requalificar tais lugares da cidade e oferecer a esses espaços novos papéis na cidade. Na cidade de Quelimane, podem ser encontrados novos edifícios públicos erguidos, como são o caso da Direção Provincial de Economia e Finanças, a Procuradoria Provincial, o Instituto Nacional de Segurança Social (INSS), a Assembleia Provincial, o Hotel Elite, a Universidade Politécnica, entre outros. A Figura 2 mostra três desses edifícios, nomeada- 
mente o INSS, o muro do futuro Condomínio dos membros do Governo Provincial e a UPQ.
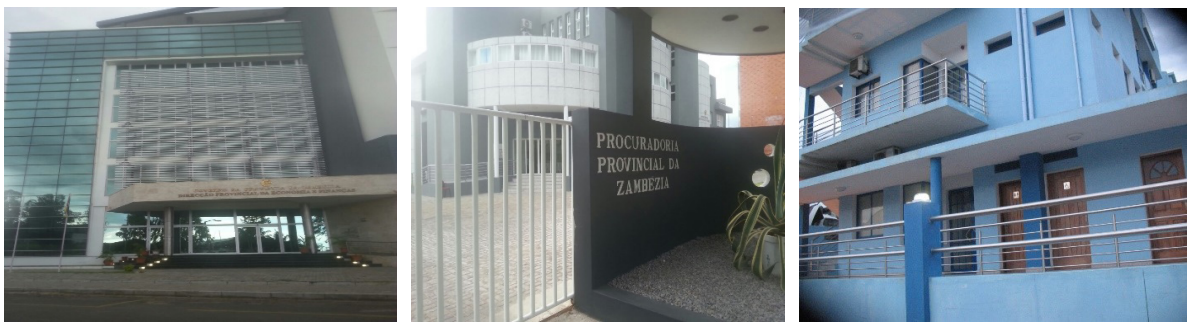

Figura 2 - Implementação de novos projetos com o objetivo de preencher os espaços vazios em Quelimane: A - Edifício da Direção de Economia e Finanças; B - Edifício da Procuradoria Provincial; C - Edifício da Delegação do Instituto Nacional de Segurança Nacional. Fotos: Klayde Evaristo, 2017.

Já na área suburbana está sendo erguido o campus da Universidade Pedagógica de Quelimane (UPQ) e, um pouco por todos os bairros de expansão, casas de singulares, algumas das quais de mais de 2 andares, oferecem condições providenciadas em edifícios que indicam a modernidade, como a instalação de sistemas de segurança em circuito fechados ou com guardas armados (Figura 3).

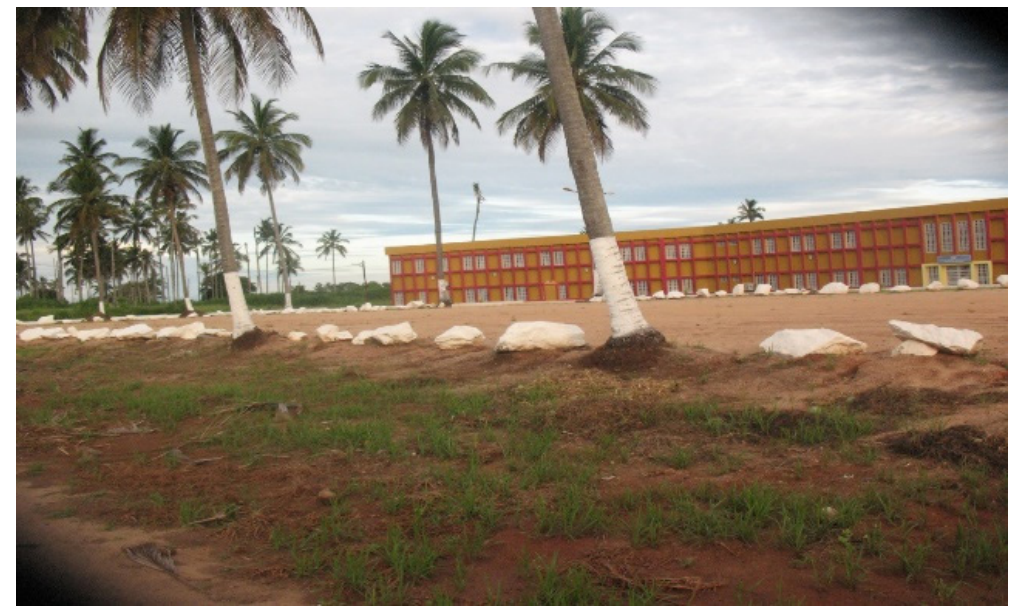

Figura 3 - Implementação do Campus de Raiz da UPQ em Murropué.

Foto: Klayde, 2017.

No entanto, na cidade de Quelimane, este aproveitamento dos baldios para a implantação de projetos ainda é incipiente, pois ainda se denota espaço constituído por edificações de subúrbios no centro da cidade, como é o caso do bairro Cansa, Chabeco e Torrone Velho. 
A expansão urbana é uma das expressões mais concretas do processo de produção do espaço na sociedade contemporânea. No espaço urbano,

[...] a concentração espacial de pessoas na forma de força de trabalho e de mercado consumidor, aliada à concentração dos meios de produção, permite que as forças produtivas alcancem um elevado grau de desenvolvimento, acelerando assim a realização da mais-valia e a reprodução do capital, e ao mesmo tempo levando a uma concentração populacional ainda maior (NASCIMENTO et al., 2011, p.45).

Portanto, a urbanização reflete a dinâmica de acumulação e concentração do capital na cidade e reproduz a aglomeração ao demandar cada vez mais espaço. Mas a cidade, mais do que um local de produção e consumo de mercadorias e de habitação, parafraseando Nascimento (2011), é também um importante lugar de vivência humana em sua dimensão plena, e seu espaço reflete e condiciona as diversas estratégias engendradas pelos diferentes agentes sociais na criação e apropriação da riqueza, da reprodução da força de trabalho e do desenrolar da vida cotidiana como um todo.

Diante do aumento da necessidade de locais para o desenvolvimento de atividades produtivas e para a constituição de áreas habitacionais, a expansão da área urbana se dá em direção a terras até então utilizadas para fins agropecuários, ou mesmo em áreas marginais com fortes potencialidades de riscos de várias ordem, sendo estas anexadas ao perímetro urbano. Este fenômeno é patente em Quelimane, pois os espaços expandidos com esses objetivos estão sendo usados para acomodar habitações, o que leva a crer que aqui também a produção do espaço urbano está diretamente veiculada à dinâmica de capitais, ou então pela economia da pobreza dos vientes (os novos que chegam à cidade) porque a obtenção desse espaço é feito por aquisição monetária e a preços cada vez mais exorbitantes dada a demanda, o que contraria a Lei Mãe, a Constituição da República de Moçambique (CRM, 2008) no número 1 e 2 do artigo 109. Recorde-se que este artigo reza que a terra é propriedade do Estado e que ela não pode ser vendida, ou por qualquer outra forma alienada, nem hipotecada ou penhorada.

Este princípio inspira-se não no modelo de orientação socialista como também coaduna com os saberes locais dos moçambicanos, pois a terra, segundo Alassan e Ndau, citado por Ngoenha (1994:27), "não é propriedade da família, nem da povoação e da tribo, mas estes são apenas beneficiários". A natureza, ou seja a terra, "é propriedade divina, pois para os saberes locais ou melhor na epistemologia africana, a natureza é um órgão vivo e podem ser desvendados os seus segredos recorrendo a mitos". Por isso, para que "o sujeito conheça uma coisa tem que estar em união com ela, tem que estar no seu interior e abordá-la a partir daí. Para que o sujeito possa conhecer algo deve ir ao 'coração das coisas'”' (Idem).

Contudo, o crescimento na demanda por espaços incentiva a acelerada expansão urbana, mas não há uma relação direta entre a demanda e a rapidez com que as novas áreas são urbanizadas, nem com o grau em que ocorre a ocupação efetiva dessas terras. A explicação está na condição particular de mercadoria assumida pela terra no espaço urbano, introduzido pela expansão mercantil e o modo de produção capitalista. 


\section{O Solo Urbano como Meio de Troca}

A importância da terra urbana enquanto condição essencial para a realização de qualquer atividade, somada às suas propriedades intrínsecas (sobretudo condições físicas), confere a ela o carácter de mercadoria, assumindo assim um determinado preço a ser pago pelos indivíduos desprovidos do direito de propriedade privada, o que contraria com todo o quadro legal do País.

Enquanto simples matéria, elemento da natureza, a terra não possui valor, pois não pode ser reproduzida pelo trabalho humano. Todavia, enquanto componente do espaço geográfico, "a terra transcende a condição de mera superfície, sítio das edificações, e agrega atributos específicos que viabilizarão, em maior ou menor grau, as necessidades de produção e consumo no espaço urbano" (SINGER, 1982; RIBEIRO, 1997, p. 93).

Em função disso, pode-se dizer que a terra urbana assume a condição de "terra mercadoria", apresentando um valor de uso, dado pela "sua condição de elemento vital, não reprodutível e indispensável à atividade humana, além de um valor de troca, pois diante da demanda e da possibilidade iminente de acumulação de riqueza que a mesma representa a quem tenha sua posse, assume um preço" (HARVEY, 1980, p.108).

Paradoxalmente, os espaços que hoje estão sendo urbanizados antes pertenceram ao meio rural ou ao menos ruralizado em que os camponeses herdaram dos seus antepassados vastas áreas de terra e continuam proprietárias das mesmas, mas sem o mínimo conhecimento do seu real valor enquanto componente do espaço geográfico, pois para os saberes locais a terra é do divino e não pode ter preço por não constituir objeto de troca. De fato, em Moçambique e Quelimane em particular, para além de terras de indivíduos que as herdaram, há terras que eram propriedade de latifundiários ou empresas majestáticas, resultantes de um processo longo e conturbado de expropriação, que foram nacionalizadas no pós-independência.

Há necessidade de se harmonizar as temáticas de obtenção e as funções para que se destina o espaço, pois a mercadoria "terra urbana" não pode ser entendida dissociada dos objetos que constituem o espaço da cidade, que se prende com "as condições do sistema viário, a disponibilidade de serviços públicos e, principalmente, a sua posição em relação a outros objetos espaciais fundamentais como os centros de trabalho e consumo, pois são esses objetos os elementos que agregam valor a ela". (RIBEIRO, 1997, p. 52).

Nesta via de análise, a terra deve ser considerada, de acordo com Vilaça (1998), a partir de um valor conferido pela sua localização no espaço da cidade, o seu preço e remuneração a ser paga por ela no mercado:

[...] há dois valores a considerar no espaço urbano. O primeiro é o dos produtos em si - os edifícios, as ruas, as praças, as infraestruturas. O outro é o valor produzido pela aglomeração, dado pela localização dos edifícios, ruas e praças, pois é essa localização que os insere na aglomeração. A localização se apresenta, assim, como um valor de uso da terra - dos lotes, das ruas, das praças, das praias - o qual, no mercado, se traduz em preço da terra. Tal como qualquer valor, o da localização também é dado pelo tempo de trabalho socialmente 
necessário para produzi-la, ou seja, para produzir a cidade inteira da qual a localização é parte (VILLAÇA, 1998, p. 334).

A localização aparece como principal valor de um determinado fragmento do espaço urbano em virtude das vantagens que a mesma pode proporcionar na realização das atividades econômicas ou à função residencial. É daí que as terras no centro da cidade são mais valorizadas que as das áreas de expansão.

Para as empresas, a disponibilidade de localizações favoráveis é fundamental para usufruir das vantagens de aglomeração, como o acesso aos principais mercados consumidores, a proximidade a atividades complementares e, principalmente para as indústrias, condições adequadas para o transporte de mercadorias. Razão pela qual uma das grandes prioridades no processo de expansão da cidade é apetrechá-la de vias de acesso para os diferentes pontos estratégicos ao nível da cidade, bem como para áreas de produção socioeconômica mesmo que para o meio rural.

Nestas condições, Ribeiro (1997, p. 45) referiu que a cidade assume o papel de "uma força produtiva social espacial, cuja utilização permite aumentar a produtividade do trabalho e diminuir o tempo de rotação do capital, o que se traduz em maior rentabilidade dos investimentos realizados". Mais do que isso, ainda nas palavras do autor, as empresas passam então a disputar as localizações mais vantajosas, visando, com isso, obter o "controlo de certas condições da produção não reprodutíveis, portanto, monopolizáveis, geradoras de sobre lucros de localização" (Idem, p. 46).

Por sua vez, Vilaça (1998) referiu que, para a função habitacional, a localização é importante ao condicionar a acessibilidade do indivíduo aos demais pontos da cidade, seja para a realização da produção enquanto força de trabalho, seja para o próprio consumo do espaço. No entanto, cabe aqui acrescentar que tudo depende da disponibilidade dos maios de transporte para garantir a mobilidade das pessoas de um lugar a outro.

Em certa medida, também importarão aspectos referentes ao padrão social do bairro, bem como a presença de amenidades físicas, que incidem sobre o poder de atratividade da área às camadas de média e alta renda.

As periferias urbanas sobretudo as produzidas pela expansão possuem características antagônicas que às acima mencionadas, uma vez que, de acordo com Corrêa (2008), constituem aquela área da cidade que em termos de localização se situa nos arredores do espaço urbano. Para o autor, trata-se de uma faixa periférica que, "a cada momento que se considera inclui: a) áreas que se acham urbanizadas e nos limites do espaço urbano contínuo; b) áreas onde a urbanização ainda e incipiente, coexistindo com áreas de agricultura, ora intensiva, ora extensiva, ou então marcada por uma forte esterilização" (CORRÊA, 2008, p. 3).

Ainda de acordo com o autor, as estratégias e ações dos proprietários fundiários e dos meios de produção, os promotores imobiliários, o Estado e os grupos sociais excluídos no contexto da sociedade capitalista são determinantes para a configuração do espaço urbano tal e qual se conhece, carregando em sua formação uma herança de conflitos e desigualdades.

De igual modo, "as estratégias adoptadas por esses agentes variam no tempo e no espaço, em virtude de causas externas e de contradições inerentes ao movimento geral de acumulação capitalista" (Idem, citado por FERREIRA, s/d, p. 8). 
Neste contexto, os dois primeiros agentes especulam e moldam o espaço mediante as necessidades da demanda populacional de média e alta renda, ou seja, os que podem pagar para utilizarem o espaço urbano. O autor também dá a entender que "os grupos sociais excluídos, ao produzirem casas de lata, invadindo terrenos públicos ou privados, tornam-se, efetivamente, agentes modeladores, produzindo seu próprio espaço" (FERREIRA s/d, p.198). Da mesma forma, Souza (2000) complementa que "o modo de produção capitalista produz novas formas e origina paisagens com características cada vez mais urbanas".

Com as abordagens, deixadas por esses autores, pode-se entender que as características desiguais incluindo as próprias precariedades socioespaciais ditam a essência do que pode ser considerado como meio urbano em função das suas características. Dito por outras palavras, o meio urbano é e deve ser caracterizado por áreas dotadas de infraestruturas de gabarito, de bens e serviços especializados no centro, com uma periferia urbana caracterizada por carência de tais infraestruturas e abundância de serviços não especializados.

Isso quer dizer que o mais provável é que, por mais que se melhorem as condições socioespaciais das periferias expandidas, ter-se-á sempre áreas menos urbanizadas, já que, como se afirmou anteriormente, as cidades foram edificadas sobre uma pequena porção do meio rural, ao que indica que ainda existe muito espaço rural em volta do que já foi ou ainda se pretende urbanizar com a política de expansão das cidades.

Há que se destacar que "quanto mais espaço urbano se produz, mais elevado é o preço da terra urbanizada e mais evidente a expulsão dos trabalhadores para áreas menos urbanizadas e quanto mais áreas nobres se expandem, [...] maior é a renda, lucros e juros, apropriados por parcelas de classes" (SINGER, 1982, p. 43).

De acordo com Damiani, fora do circuito da riqueza, é visível:

... a outra face do urbano, em geral nas periferias distantes e nas áreas centrais degradadas. São nelas que trabalham, moram e circulam os trabalhadores, nelas se encontram em bairros de lata, ocupações coletivas de terra, casas precárias, conjuntos habitacionais de casas ou apartamentos com dimensões mínimas, edifícios precários utilizados para escolas, creches, postos de saúde, hospitais (DAMIANI, 2006, p. 44).

Mais do que isso, "nessas áreas, os trabalhadores não desaparecem após a jornada de trabalho e sua presença torna visível a desigualdade socioespacial", como referiu Soares (2007, p. 64). Este cenário é visível na cidade de Quelimane com a invasão massiva de sujeitos que vêm praticar a atividade de "taxistas de bicicleta", que permanecem durante a semana e regressam à zona de origem nos finais de semana para se juntarem a suas famílias e a coetâneos.

Nos bairros periféricos ou "cidade caniço", segundo ARAúJO (2003, p. 38), "as ruas são estreitas, sujas, esburacadas, com pouca ou nenhuma iluminação pública por onde circulam ônibus ${ }^{1}$, minibuses, camiões, carros velhos de segunda ou terceira mão, que colocam em risco a vida dos que neles são transportados".

Como se referiu anteriormente, estas paisagens sociais constituem características típicas do meio urbano, onde é visível a presença diária dos trabalhadores que nela circu- 
lam para fornecer a força de trabalho nas atividades no meio urbano que requerem uma força de trabalho segunda ou terciária e pouco remunerada, como operários, latoeiros, pedreiros, ferreiros, carpinteiros, "taxistas de bicicleta", entre outros.

E é muito vantajoso ter esses agentes sociais por perto para que, a qualquer momento, possam servir as necessidades urbanas dentro ou fora do seu horário normal de trabalho. Também podem ser incluídas nesse processo as atividades que as mulheres da mesma classe exercem como empregadas domésticas nas casas dos funcionários públicos e privados da classe média e alta, cuidando da limpeza da casa, das crianças e das refeições.

Outro elemento característico deixado pelos sujeitos que moram ou frequentam a cidade e que se tornou um estilo de vida próprio das cidades é a venda e revenda de produtos diversos por ambulantes que circulam por todas as ruas e avenidas da cidade, vendem nas esquinas dos passeios do centro da cidade, controlam e lavam carros nas ruas muito bem frequentadas. Então não se pode negar que esses fenômenos criados pelo déficit econômico dos trabalhadores terceirizados constitui característica típica do meio urbano e fazem parte do ambiente que caracteriza o dia a dia das cidades, incluindo aí a criminalidade, a prostituição em ruas e avenidas, a privatização de espaços públicos ${ }^{2}$ e o vandalismo sucessivo. Todos estes aspectos são encontrados na cidade de Quelimane e fazem a paisagem urbanística do dia a dia dos munícipios.

\section{Restruturação Urbana e Novas Centralidades: uma Possibilidade}

Constitui foco deste ponto a reflexão sobre as tendências de evolução da urbanização que ocorre na cidade de Quelimane a partir das resultantes da influência da modernidade e globalização, como é o caso de sucessões urbanas.

Na virada da primeira década do século XX, iniciou um novo fenômeno na cidade de Quelimane, que se assemelha ao verificado nos Estados Unidos da América e na França nos finais da década de 1970 que tem a ver com a sucessão urbana ou simplesmente urban sprawl ${ }^{3}$. Esse fenômeno está ligado ao fato de que os que detém poder econômico estão empurrando os sujeitos mais modesto, aqueles de menor posse, da cidade para o subúrbio. No entanto, os sujeitos que hoje empurram os pobres acabam sendo empurrados por outros mais tarde, porque os poderosos adquirem propriedade de pessoas pobres e empurra-nos para lugares cada vez mais distantes da cidade ou mesmo para zonas de expansão. Mais tarde, esses novos proprietários vendem a benfeitoria a grupos econômicos maiores, e assim sucessivamente. Este fenômeno ficou conhecido em Moçambique como a "venda de chaves" por parte de pessoas de baixa renda que viviam em casas alugadas no período de pós-nacionalização a novos-ricos emergentes, indo depois erguer as suas novas moradias nas áreas de expansão (LIMA, 2016).

Em Quelimane e em muitas outras cidades, pequenas, médias e grandes, está surgindo gradualmente, a partir do início deste século, uma variante do fenômeno de sucessões urbanas quando alguns empreendedores requereram o direito de uso e aproveitamento de terra (DUAT) em lugares distantes da cidade antiga, iniciando com a implantação de sítios, onde plantaram árvores frutíferas e fizeram criação de gado e 
aves, e mais tarde ergueram casas, algumas das quais evidenciando comodidades da modernidade. Ultimamente esses sítios têm sido transformados em lugares de lazer, pela beleza criada, alguns dos quais dispõem de salões de festas e locais de acomodação (Idem).

Paralelamente à sucessão urbana, ocorre a expansão de serviços bancários a lugares dos subúrbios, o que está definindo novas centralidades (Silva, 2017, 2009 e 2004). Tais serviços formam novos lugares de encontro e reencontros entre pessoas de diferentes origens e até de nacionalidades. Além disso, as novas centralidades unem sujeitos da mesma etnia ou da mesma religião, criando determinadas microterritorialidades tidos como microcosmos, que têm sentido particular de confrontação com o contexto excessivo da cidade, dando lugar a formação de espaços com certas especificidades, que as torna únicas e visíveis (FORTUNA, 2012).

Em suma, na cidade de Quelimane são encontradas várias centralizadas, que são definidas segundo o tipo de ator que mais influência cria.

\section{Considerações Finais}

Na cidade de Quelimane, ocorre uma dinâmica intensa de vários atores que definem e reestruturam a cidade, indicando a futura direção para onde poderá drenar a requalificação urbana.

Esses atores são os agentes econômicos, em particular desempenhado pelos proprietários das PME's, das agências de instituições financeiras e de instituições públicas (Universidade e Hospital Central), mesmo dos informais que definem novas centralidades e lugares de sublimação.

No entanto, fica claro que a nova requalificação deve tomar uma abordagem inclusiva, aquela que olha para as nuances, aqueles lugares que poucas pessoas conseguem perceber, que na maioria das vezes são únicas e as suas dinâmicas, assim como a cultura dos povos que aí habitam e habitarão.

\section{Referências Bibliográficas}

ARAÚJO, M. G. Geografia dos Povoamentos: Assentamentos humanos rurais e urbanos, Maputo: UEM, 1997.

. Ruralidades-urbanidades em Moçambique: conceitos ou preconceitos? Geografia: revista da Faculdade de Letras e Geografia, Porto, I Série, v. XVII-XVIII, 2002.

Os espaços urbanos em Moçambique. GEOUP: Espaços e tempos, São Paulo, 2003.

ARROYO, M. M. Dinâmica territorial, circulação e cidades médias. In: SPOSITO, E. S. SPOSITO, M. E. B. SOBARZO, O. (orgs.). Cidades médias: produção do espaço urbano e regional. São Paulo: Expressão Popular, 2006. (Série Geografia em Movimento). 
CAVALCANTI, L. S. Uma geografia da cidade - elementos da produção do espaço urbano. In: CAVALCANTI, L. S. (org.). Geografia da cidade: a produção do espaço urbano de Goiânia. Goiânia: Alternativa, 2001.

CMCQ. Conselho Municipal da Cidade de Quelimane, 2016.

CONSTITUIÇÃO DA REPÚBLICA 2004. Imprensa Nacional de Moçambique, edição 2008 (atualizada). Maputo, 2008.

CORRÊA, R. L. A periferia urbana. Geosul, v. 1, n. 2, 1986.

. O espaço urbano. 4. ed. $2^{\text {a }}$ reimpressão. São Paulo: Ática, 2000.

Estudos sobre a rede urbana. Rio de Janeiro: Bertrand Brasil, 2006.

Técnica, espaço, tempo: globalização e meio técnico-científico-informacional.

2. ed. São Paulo: Hucitec, 1996.

DAMIANI, A. L. Cidades médias e pequenas no processo de globalização: apontamentos bibliográficos. In: LEMOS, A. I. G.; ARROYO, M.; SILVEIRA, M. L. (orgs.). América Latina: cidade, campo e turismo. CLACSO, Conselho Latino-americano de Ciências Sociais, São Paulo: Dezembro/2006.

FERREIRA, M. C. P. P. A Produção desigual do espaço urbano: considerações sobre a Política Habitacional de Interesse Social no município de Parnamirim/RN. São Paulo, S/D.

GOTTDIENER, M. A produção social do espaço urbano. Tradução de Geraldo Gerson de Souza. São Paulo: Edusp, 1993.

HARVEY, D. A justiça social e a cidade. São Paulo: Hucitec, 1980.

. The condition of postmodernity: an enquiry into the origins of cultural change. Cambridge, MA; Oxford, UK: Blackwell, 2007.

LIMA, J. C. M. Plano de estrutura urbana de Mocuba, Dissertação de Master en Planificacion, Gestão Ambiental e de los Recursos Naturales, Fundación General da la Universidad Politécnica de Madrid, Madrid, CEPADE, 2010.

Planificação territorial, desenvolvimento urbano: tendências históricas de Quelimane, Quelimane, MIMEO, 2012.

. Os Circuitos da economia e as desigualdades sociais em Mocuba: Uma Abordagem Espacial e Escalar. In: III Simpósio Internacional Cidades Médias, Rio de Janeiro - RJ. Anais..., UFRJ/ReCiMe, 2015. 
. Conflito entre saberes na urbanização: as tradições das comunidades e o planeamento de Estado na cidade de Mocuba. Tese (Doutorado). Faculdade de Ciências da Terra e Ambiente, Universidade Pedagógica de Moçambique, Maputo, 2016

NGOENHA, S. O retorno de bom selvagem: uma perspectiva filosófica africana do problema ecológico. Porto: Salesianas, 1994.

SANTOS, M. A natureza do espaço: técnica e tempo. Razão e emoção. São Paulo: Hucitec, 1996.

Territórios: estudos sobre o ordenamento territorial. (Coleção espaço, território e paisagem). 2. ed. Rio de Janeiro: DP\&A, 2006.

A urbanização brasileira. (Coleção Milton Santos). 5. ed. São Paulo: Edusp, 2005.

A natureza do espaço: técnica e tempo, razão e emoção. 4. ed. São Paulo: Edusp. 2008.

SILVA, W. R.; SPOSITO, M. E. B. (orgs.). Perspectivas da urbanização. Reestruturação urbana e das cidades. Rio de Janeiro: Consequência, 2017.

SILVA, W. R. Centralidade, shopping centers e reestruturação das cidades médias. In: MAIA, D. S.; SILVA, W. R. da; Withacker, A. M. (orgs.). Centro e centralidade em cidades médias. São Paulo: Unesp - Cultura Acadêmica, 2017. p. 199-226.

O papel das cidades médias diante da reestruturação urbana. In: BICALHO, A. M. M. S.; GOMES, P. C. C. (orgs.). Questões metodológicas e novas temáticas na pesquisa geográfica. Rio de Janeiro: Publit, 200. p. 125-140.

Novos centros, novas centralidades, novas diferenças. A fragmentação do espaço urbano de Londrina. Geografia (Londrina), Rio Claro, v. 29, n.1, p. 55-70, 2004.

SINGER, P. O uso do solo urbano na economia capitalista. In: MARICATO, E. (org.). A produção capitalista da casa (e da cidade) no Brasil industrial. 2. ed. São Paulo: Alfa-Ômega, 1982.

SOARES, P. R. Cidades médias e aglomerações urbanas: a nova organização do espaço regional no Sul do Brasil. In: SPOSITO, E. S. SPOSITO, M. E. B. SOBARZO, O. (orgs.). Cidades médias: produção do espaço urbano e regional. São Paulo: Expressão Popular, 2006. (Série Geografia em Movimento).

SPOSITO, M. E. B. Desafios para o estudo das cidades médias. In: XI Seminário Internacional de la Red Ibero-americana de Investigadores sobre Globalización y Território, 2010, Mendoza. Trabalhos completos. Mendoza: UNCUYO - Universidade de Cuyo. 2010. 
VERDI, A. R.; PIRES, E. L. S. As dinâmicas territoriais locais na globalização. Santa Cruz do Sul: Edunisc, 2008.

VILLAÇA, F. Espaço intraurbano no Brasil. São Paulo: Estúdio Nobel, FAPESP, Lincoln Institute, 1998.

A recente urbanização brasileira. In: CASTRIOTA, L. B. (org.). Urbanização brasileira: redescobertas. Belo Horizonte: C/ Arte, 2003.

Recebido em: 1/8/2017 Aceito em: 10/10/2017

${ }^{1}$ Conhecidos em Moçambique por machimbombos.

${ }^{2}$ Conhecidos localmente como boutique inclina, pelo fato dos produtos serem estendidos no chão, e para escolher, o interessado terá que se baixar ou se inclinar e daí o nome.

${ }^{3}$ Urban sprawl é resultado da combinação da promoção de construções de vastas super autoestradas fazendo com que o automóvel seja o principal meio de transporte urbano e a criação de um mercado imobiliário (So e Getrels, 1980). Hanchett (2000) acrescenta como fatores que favorecem ao urban sprawl as iniciativas indiretas para a suburbanização dos subsídios federais para a construção dos sistemas municipais de esgotos, o relaxamento de taxas de mais-valia aos proprietários de imóveis resultantes do ganho de capitais na venda de casas. 